\title{
Immediate Effect of Mental Imagery Training on Accuracy of Basketball Free Throws in Bangladesh
}

\author{
Md. Hamidur Rahman ${ }^{1 *}$, Muhammad Shahidul Islam² \\ ${ }^{1}$ Assistant Professor, Department of Physical Education and Sports Science, Jashore University of Science and Technology, Jashore, \\ Bangladesh \\ ${ }^{2}$ Research Scholar, Department of Physical Education and Sport Science, Visva-Bharati University, Santiniketan, West Bengal, India
}

DOI: $10.36348 /$ jaspe.2021.v04i04.004

| Received: 26.02.2021 | Accepted: 10.04.2021 | Published: 15.04.2021

*Corresponding author: Md. Hamidur Rahman

Email:_hamid.just@yahoo.com

\section{Abstract}

Mental imagery (MI) training is a useful experience to improve basketball free-throw (FT) shooting accuracy. The purpose of this study was to examine the immediate effect of mental imagery training on the improvement of free-throw shooting accuracy in basketball. Twenty (20) male basketball players were randomly selected as subjects. All subjects were randomly assigned into two groups: the experimental group $(n=10)$ and the control group $(n=10)$. A pre-test and post-test were given to every subject and each subject performed ten (10) free throws. For statistical analyses, the average values of these ten (10) free throws were used. There was a single conduct session (MI) with the experimental group lasting about ten minutes. Descriptive statistics, inferential statistics- dependent t-test, and one-way analysis of variance (ANOVA) were applied in the study, and the level of significance was $p<0.05$ and $p<0.01$. Paired sample $t$-test of the experimental group ware statistically significant $(\mathrm{p}<0.01)$ and the control group was also statistically significant $(\mathrm{p}<0.05)$ difference between pre-test and post-test values. However, the mean values of the post-test showed that the experimental group (mean number of successful free throws $=7.30$ ) had a higher average number of free-throw shooting accuracy than the control group (mean number of successful free throws $=6.50$ ). In conclusion, this study indicates that basketball players may benefit from mental imagery training to improve their free throw shooting accuracy.

Keywords: Mental Imagery, Training, Free Throw, Shooting Accuracy, Basketball.

Copyright (C) 2021 The Author(s): This is an open-access article distributed under the terms of the Creative Commons Attribution 4.0 International License (CC BY-NC 4.0) which permits unrestricted use, distribution, and reproduction in any medium for non-commercial use provided the original author and source are credited.

\section{INTRODUCTION}

The mind is the driving force of action because it controls the limbs of the human body. Through the power of imagination, one can portray an image of objects and can visualize the real objects or events. Such representation of objects or events in the mind is termed mental imagery.

This imagery is a multisensory immersive procedure that uses as many senses as possible to create and process a mental image without using external stimuli. In most athletic events, the state in which people imagine themselves while influencing abilities to cope with upcoming duties or improve performance is referred to as imagery [1]. However, it helps to mould a lasting impression on the mind creating the real picture of objects or events. Deliberation, ready wit, retentive power of the mind is playing vital roles in this regard. After all, mental imagery leads to slowness, quickness, the right timing of real activity by giving birth to intelligibility and adaptability to the instant situation as happens in games and sports. In this connection, one study demonstrates the importance of a comprehensive clinical evaluation or management of binocular vision in sports, stressing the significance of a thorough clinical evaluation or management of binocular vision in sports. Besides, the accuracy of basketball free throws is based on binocular vision [2].

Mental imagery [1] is denoted as "a symbolic sensory experience that may occur in any sensory mode" [3]. Researchers [4] stated that the faster the stimulus reaches the motor cortex, the faster the response time will be. There are two kinds of mental skills training methods: Mental rehearsal, mental imagery and imagination, visuomotor action rehearsal, and cognitive-behavior therapy are also examples of cognitive methods. Biofeedback, progressive muscle relaxing, and meditation is examples of somatic 
methods [5]. According to [6] recommended that using mental imagery evolves training sessions, competition, cognition, and motivation for young athletes in sports. Practically, everyday experiences substantiate stretching and flexibility, increase and optimize the sense, habit, mental relaxation, and perfection of sportsrelated behaviors [7].

Basketball is a popular team game played on an intermittent nature. In basketball, free-throw shooting should be a simple skill, with players alone behind the free-throw line, 5.80 meters from the end line, and no opponents or distracting elements [8]. Every player gets a chance to perform free throws after being fouled. The free throw is the easiest shot for many reasons, but it sometimes may be very difficult because of the various pressures of the game, emotional stress, and its accompanying responses [9]. Researchers $[10,11]$ found that professional basketball shooters predict free-throw outcomes with higher accuracy than non-elite players when watching video clips (MI) of free throws. As a consequence, shooting accuracy affects on the match's outcome in all types of games and sports [12] and this outcome can improve significantly if physical exercise is combined with mental imagery, according to researcher [13].

To summarise, the present researchers hypothesized that mental imagery training could improve basketball free-throw accuracy. The goal of the study was to see if mental imagery training has any immediate impact on improving free-throw shooting accuracy in basketball. Hence, the issue is explained as follows: Immediate effect of mental imagery training on basketball free throws accuracy in Bangladesh.

\section{MATERIALS AND METHODS}

Twenty male basketball players were randomly selected as subjects. The age of the subjects ranged from 17 to 24 years and data were collected at Rajshahi District Sports Association (RDSA), Rajshahi, Bangladesh. All players were competing at different basketball leagues, tournaments, and inter-university competitions. Players were randomly divided into two groups: experimental group 10 players and control group 10 players. All subjects voluntarily participated in this present study.

Table-1: The characteristics of the subjects (Mean \pm SD)

\begin{tabular}{|l|l|l|}
\hline Items & $\begin{array}{l}\text { Experimental Group } \\
(\mathbf{n = 1 0})\end{array}$ & $\begin{array}{l}\text { Control Group } \\
(\mathbf{n = 1 0})\end{array}$ \\
\hline Age (yr) & $20.10 \pm 1.97$ & $19.80 \pm 1.69$ \\
\hline Training Age (yr) & $4.95 \pm 2.15$ & $4.70 \pm 1.18$ \\
\hline Weight $(\mathrm{kg})$ & $68.10 \pm 3.72$ & $67.20 \pm 3.49$ \\
\hline Height $(\mathrm{cm})$ & $177.2 \pm 8.31$ & $174.7 \pm 7.42$ \\
\hline Body Mass Index (BMI) & $19.49 \pm 0.82$ & $19.25 \pm 0.99$ \\
\hline
\end{tabular}

During the day of the experiment, all subjects participated in the pre-test as well as a post-test, and the number of free throws performed limited to ten (10). After the pre-test, the experimental group received their treatment (MI) for one conduct session and the session lasted for ten minutes. The session was divided into two parts; the first five minutes included the progressive muscle relaxation method [14] and the next five minutes of mental imagery technique [15].

Subjects were instructed on the proper techniques of relaxation and imagery. They were instructed to lie comfortably on their backs, close their eyes, and take two deep breaths, in and out, in and out, to begin the relaxation and imagery session. Tensing and relaxing various muscle groups make up progressive relaxation. Arms, facial and neck muscles, back and chest muscles, and legs were the muscle groups that were used. During this period, the researchers paid close attention to the feelings of tension and relaxation. Progressive relaxation was designed to aid in the lowering of muscle tension [14]

The mental imagery portion begins after the relaxation session. The subjects were directed "Concentrate on visualizing effective free throws. The investigators want to put themselves in the shot of the players to see how they would perform the shooting. Feel the presence of players on the free-throw line. Hold the ball in front of their chest while separating their legs from their bodies and bending their knees slightly. Players keep the balls with shooting hands by bouncing. Line up an index finger with the valve on the ball in a relaxed hand stance. Place their off-hand on the ball's side. Face the basket with their shooting hand's thumb pointing toward the center of forehead. Extend the arm forcefully and flick the wrist to make a backspin, then straighten the knees and lift onto the toes, balancing on them. Keeping eyes on the target and shooting arm up, the wrist was cocked downward until the ball reached the basket during the follow-through". Finally, players should be able to feel and see each freethrow land in the basket [15].

The imagery technique was most effective when used for about five minutes [16]. The control group received no treatment and they maintained their regular schedule practice. Again all subjects were conducted for the post-test using the same basket that they were at for the pre-test. The number of successful free throws during the pre-test and post-test periods was recorded by the investigators. 
Hamidur Rahman \& Muhammad Shahidul Islam., J Adv Sport Phys Edu, Apr, 2021; 4(4): 68-72

The data were analyzed using descriptive statistics; mean, standard deviation (SD), standard error of mean (SEM), best and worst score. Inferential statistics- dependent t-test, and one-way analysis of variance (ANOVA) was applied to check the level of

significance. The analysis was performed with SPSS version 20.0 for Windows. The significance level was set at $\mathrm{p}<0.05$ and $\mathrm{p}<0.01$

\section{RESULTS}

Table-2: The free throw shooting between pre-test and post-test of experimental and control group

\begin{tabular}{|l|l|l|l|l|l|l|}
\hline \multirow{2}{*}{ Group } & \multirow{2}{*}{ Test } & \multicolumn{6}{|c|}{ Descriptive Statistics } \\
\cline { 3 - 7 } & & Mean & SD & SEM & Best Score & Worst Score \\
\hline $\begin{array}{l}\text { Experimental } \\
(\mathrm{n}=10)\end{array}$ & Pre-test & 5.70 & 0.95 & 0.30 & 7 & 4 \\
\cline { 2 - 7 } & Post-test & 7.30 & 0.67 & 0.21 & 8 & 6 \\
\hline $\begin{array}{l}\text { Control } \\
(\mathrm{n}=10)\end{array}$ & Pre-test & 5.60 & 1.07 & 0.34 & 7 & 4 \\
\cline { 2 - 7 } & Post-test & 6.50 & 0.85 & 0.27 & 8 & 5 \\
\hline
\end{tabular}

Legend: SD = Standard Deviation; SEM = Standard Error of Mean

Table- 2 expressed the descriptive statistics of the free throw shooting between pre-test and post-test of experimental and control group. The experimental group pre-test mean $=5.70$ and $\mathrm{SD}=0.95, \mathrm{SEM}=0.30$, best score $=7$, and worst score $=4$, whereas for posttest mean $=7.30$ and $\mathrm{SD}=0.67, \mathrm{SEM}=0.21$, best score
$=8$, and worst score $=6$. The control group pre-test mean $=5.60$ and $\mathrm{SD}=1.07, \mathrm{SEM}=0.34$, best score $=$ 7 , and worst score $=4$, whereas for post-test mean $=$ 6.50 and $\mathrm{SD}=0.85, \mathrm{SEM}=0.27$, best score $=8$, and worst score $=5$.

Table-3: Comparison of the free throw shooting between pre-test and post-test of experimental and control group

\begin{tabular}{|c|c|c|c|c|c|c|c|}
\hline \multirow[t]{2}{*}{ Group } & \multirow[t]{2}{*}{ Test } & \multicolumn{3}{|c|}{ Descriptive Statistics } & \multicolumn{3}{|c|}{ Inferential: Paired Sample t-test } \\
\hline & & Mean Diff. & Std. Dev. & Std. Err. Diff. & $\mathbf{t}$ & df & Sig. (2-tailed) \\
\hline \multirow{2}{*}{$\begin{array}{l}\text { Experimental } \\
(\mathrm{n}=10)\end{array}$} & Pre-test & \multirow{2}{*}{1.60} & \multirow{2}{*}{0.97} & \multirow{2}{*}{0.31} & \multirow{2}{*}{$5.24 * *$} & \multirow{2}{*}{9} & \multirow{2}{*}{0.001} \\
\hline & Post-test & & & & & & \\
\hline \multirow{2}{*}{$\begin{array}{l}\text { Control } \\
(n=10)\end{array}$} & Pre-test & \multirow{2}{*}{0.90} & \multirow{2}{*}{0.99} & \multirow{2}{*}{0.31} & \multirow[t]{2}{*}{$2.86^{*}$} & \multirow{2}{*}{9} & \multirow{2}{*}{0.019} \\
\hline & Post-test & & & & & & \\
\hline
\end{tabular}

Significance level at $9 \mathrm{df}$ at $* 0.05$ level $=2.262$ and at $* * 0.01$ level $=3.250$

Table- 3 revealed that the free throw shooting between pre-test and post-test of experimental and control group shows that experimental group mean difference $=1.60$, standard deviation $=0.97$, standard error difference $=0.31, \mathrm{t}_{(9)}=5.24$ and $\mathrm{p}=0.001$, $(2-$ tailed); there is a statistically significant difference as tabulated value of $t(0.01)(9)=3.250 \& \mathrm{p}<0.01$ between pre-test and post-test values. The control group mean difference $=0.90$, standard deviation $=0.99$, standard error difference $=0.31 ; \mathrm{t}_{(9)}=2.86$ and $\mathrm{p}=0.019$, (2tailed); there is also statistically significant difference as tabulated value of $\mathrm{t}(0.05)(9)=2.262 \& \mathrm{p}<0.05$ between pre-test and post-test values. Finally results show that experimental and control group were increased in number of successful basketball free throw shooting accuracies between pre-test and post-test.

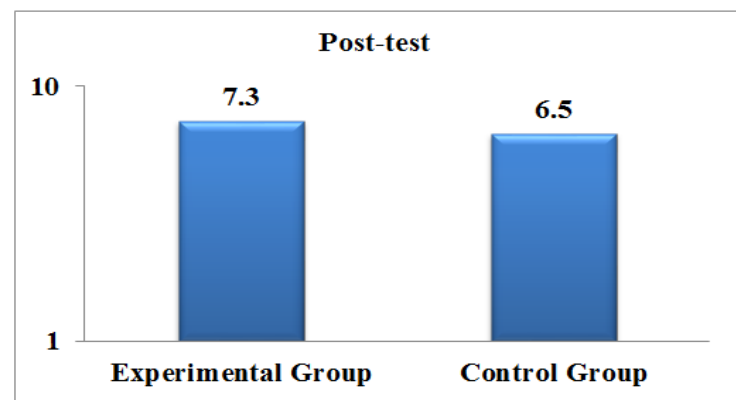

Fig-1: Mean values (post-test) of experimental and control group
However, figure 1 mean values of the post-test showed that the experimental group had a higher average number of free-throw shooting accuracy than the control group.

\section{DISCUSSION}

Table 3 shows that both the experimental and control groups improved their basketball free-throw shooting accuracy, although the increase was statistically significant. However, figure 1 showed that the mental imagery group improves more their free throw shooting performance than that of the control group. Likewise, researcher [17] investigated the imagery skill on basketball free throw shooting accuracy, and results show that imagery groups performed better from pre-to post-test than the traditional physical practice group. Further research carried out by [18] investigated the impact of mental imagery training on penalty shooting abilities in handball, finding that the experimental group performed significantly better than the control group. According to [19] used imagery training and results showed that the imagery group improved their number of free-throw shooting after observing the imagery schedule regularly. On the other hand, 120 basketball players were chosen by the researcher [20], and they were divided into three experimental groups and a control group. Finally, results show that the mental imagery 
group improved their free-throw shooting performance, and also a combination of physical and mental imagery group are statistically significant as compared to the control group. Additional studies done by [21] investigated whether mental imagery has an impact on badminton skill performance and they discovered that the scores of the experimental group were improved between pre- to post-test. Keeping this in mind, the current findings corroborate previous studies, emphasizing the significance of mental imagery training.

\section{CONCLUSION}

The main purpose of this study was to investigate whether the immediate effect of mental imagery would enhance basketball skill performance specifically on free-throw shooting. In summary from this study, it could be said that mental imagery training can improve free throw shooting accuracy in basketball skill performance.

\section{RECOMMENDATIONS}

Further research in this area should involve more conduct sessions (MI) using a larger sample size across a variety of tasks, and a similar study may be conducted on different ages, sexes, games, and sports.

\section{Limitation}

In this study, the sample sizes were too small.

\section{ACKNOWLEDGEMENTS}

The authors thank Mr. Md. Khairul Alam Forhad, Joint Secretary, Bangladesh Basketball Federation for making their resources available, and all players who have participated voluntarily in this study. The authors were highly indebted to Mr. Md. Abdul Mottalib, Assistant Professor (Retd.), Department of English, Shibganj Mahila College, Chapainawabganj, Bangladesh for his cooperation during the proofreading of this study.

\section{Financial support and sponsorship}

This research received no external funding regarding the completion of this work.

\section{Conflicts of interest}

There are no conflicts of interest.

\section{REFERENCES}

1. Di Corrado, D., Guarnera, M., Guerrera, C. S., Maldonato, N. M., Di Nuovo, S., Castellano, S., et al. (2020). Mental imagery skills in competitive young athletes and non-athletes. Frontiers in Psychology, 11(633), 1-7.

2. Vera, J., Molina, R., Cárdenas, D., Redondo, B., \& Jiménez, R. (2019). Basketball free-throws performance depends on the integrity of binocular vision. European journal of sport science, 8, 1-22.
3. Hardy, L., Jones, G., \& Gould, D. (1996). Understanding psychological preparation for sport: Theory and practice of eliteperformers. Chichester, United Kingdom: Wiley.

4. Rahman, M. H., \& Islam, M. S. (2021). Investigation of audio-visual simple reaction time of university athletes and non-athletes. Journal of Advances in Sports and Physical Education, 4(3), 24-29.

5. Behncke, L. (2004). Mental skills training for sports: A brief review. Athletic Insight The Online Journal of Sports Psychology, 6(1), 1-19.

6. Munroe-Chandler, K. J., Hall, C. R., Fishburne, G. J., \& Strachan, L. (2007). Where, when, and why young athletes use imagery. Research Quarterly for Exercise and Sport, 78(2), 103-116.

7. Rahman, M. H., \& Islam, M. S. (2020). Stretching and flexibility: A range of motion for games and sports. European Journal of Physical Education and Sport Science, 6(8), 22-36.

8. Okubo, H., \& Hubbard, M. (2006). Dynamics of the basketball shot with application to the free throw. Journal of Sports Sciences, 24(12), 13031314.

9. Grouios, G., Mousikou, K., Hatzinikolaou, K., Semoglou, K., \& Kabitsis, C. (1997). The effect of a simulated mental practice technique on free throw shooting accuracy of highly skilled basketball players. Journal of Human Movement Studies, 33, 119-138.

10. Aglioti, S. M., Cesari, P., Romani, M., \& Urgesi, C. (2008). Action anticipation and motor resonance in elite basketball players. Nat Neurosci, 11(9), 1109-1116.

11. Roumbou, S. (2017). Aristotle's concept of mental imagery in sports. Psychological Thought, 10(1), 49-59.

12. Islam, M. S., Kundu, B., \& Saha, S. (2019). Relationship between repeated sprint ability and accuracy of soccer shooting performance in young players. European Journal of Physical Education and Sport Science, 5(11), 95-104.

13. Barraclough, J. (2021). The importance of imagery in sport. Retrieved 03 20, 2021, from Believe Perform: https://believeperform.com/theimportance-of-imagery-in-sport/.

14. Bernstein, D. A., \& Borkovec, T. D. (1973). Progressive Relaxation Training: A Manual for the Helping Professions. Champaign, Illinois: Research Press.

15. Wissel, H. (2004). Basketball: steps to success. Champaign, IL : Human Kinetics.

16. Twining, W. E. (1949). Mental practice and physical practice in learning a motor skill. Research Quarterly. American Association for Health, Physical Education and Recreation, 20(4), 432-435.

17. Ziegler, S. G. (1987). Comparison of imagery styles and past experience in skills performance. Perceptual and Motor Skills, 64(2), 579-586. 
18. Arjeria, G. P., \& Kumar, S. (2015). Effect of mental imagery on penalty shooting in handball. International Journal of Physical Education, 8(1), 24-27.

19. Cannon, J. E. (2008). Effects of imagery use in basketball free throw shooting. Theses Digitization Project.

3354 , https://scholarworks.lib.csusb.edu/etd-project/3354.
20. Eckert, L. A. (1989). The effects of mental imagery on free throw performance. Kinesiology, Sport Studies, and Physical Education Master's Theses, 3 , http://digitalcommons.brockport.edu/pes_theses/3.

21. Daphne, N. C., \& Lim, B. (2016). The effects of imagery on badminton skill performance. International Journal of Health, Physical Education and Computer Science in Sports, 21(1), 10-14. 